Quality : Jurnal Kesehatan

Volume 14, Nomor 2 Tahun 2020

pISSN : 1978-4325, eISSN : 2655-2434, DOI: 10.36082/qjk.v14i2.103

\title{
KEPATUHAN KONSUMSI TABLET FE PADA IBU HAMIL
}

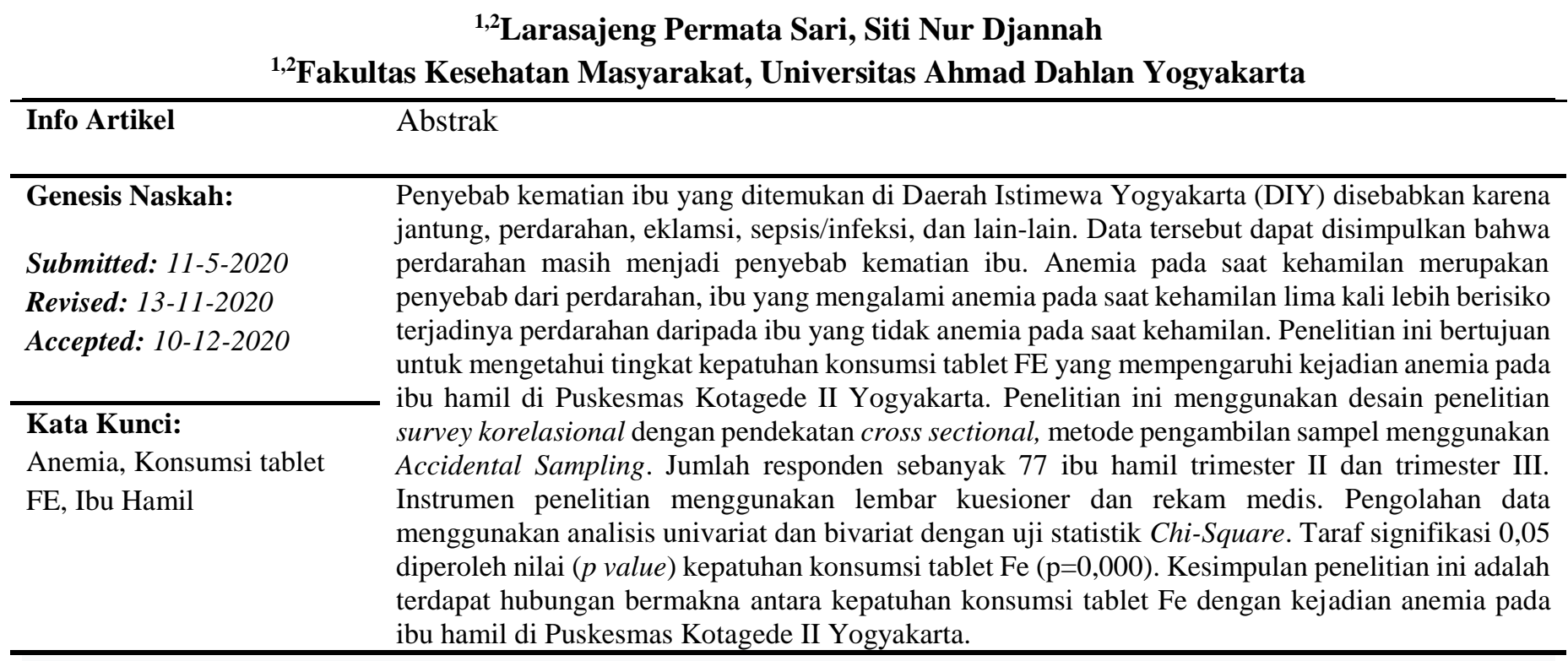

\section{COMPLIANCE WITH TABLET FE CONSUMPTION IN PREGNANT WOMEN}

\begin{abstract}
Keywords:
Anemia, Fe tablet

consumption, Pregnant

women
\end{abstract}

\begin{abstract}
Maternal mortality in Yogyakarta Special Region are caused by heart disease, bleeding, eclampsia, sepsis / infection. Bleeding is still number one causes of maternal death. Pregnancy with anemia are 5 times more at risk of bleeding than who are not. The aims of the research was to determine relationship of consumption of iron tablets with anemia in pregnant women in Kotagede II Yogyakarta Public Health Center. This was a correlational survey research design, a cross sectional approach. The sampling method uses accidental sampling technique. The number of respondents was 77 pregnant women in second and third trimester. The research instrument used questionnaire sheets and medical records. Data were processed by Chi-Square statistical tests. Study found With a significance level of 0.05, the value ( $p$ value) of compliance with Fe tablet consumption $(p=0,000)$. The conclusion of this study is that there is a significant relationship between Fe tablet consumption with the incidence of anemia at Kotagede II Yogyakarta Health Center.
\end{abstract}

\footnotetext{
Korespondensi Penulis:

Larasajeng Permata Sari

Jl. Prof.Dr.Soepomo,S.H. Janturan Yogyakarta 55164

email: larasajeng29@gmail.com
} 


\section{Pendahuluan}

Sustainable Development Goals (SDGs) merupakan upaya pembangunan berkelanjutan yang menjadi acuan dalam kerangka pembanggunan dan perundingan negara-negara di dunia sebagai pengganti pembangunan global Millenium Development Goals (MDGs) yang telah berakhir di tahun 2015. SDGs memiliki beberapa tujuan, diantaranya menjamin kehidupan yang sehat dan mendorong kesejahteraan bagi semua orang

Segala usia, dengan salah satu outputnya mengurangi Angka Kematian Ibu (AKI) hingga 70 per 100.000 kelahiran hidup (KH) pada tahun 2030. Output ini tentunya semakin turun jika dibandingkan target MDGs tahun 2015 yaitu menurunkan AKI menjadi 102 per $100.000 \mathrm{KH}$ dalam kurun waktu 1990-2015 (Kementerian Kesehatan RI Badan Penelitian dan Pengembangan, 2018)

Menurut Dinkes DIY (2017), penyebab kematian ibu yang ditemukan di DIY disebabkan karena jantung, perdarahan, eklamsi, sepsis/infeksi, dll. Data tersebut dapat disimpulkan bahwa perdarahan masih menjadi penyebab kematian ibu. Anemia pada saat kehamilan merupakan penyebab dari perdarahan, ibu yang mengalami anemia pada saat kehamilan 5 kali lebih berisiko terjadinya perdarahan daripada ibu yang tidak anemia pada saat kehamilan (Dinkes DIY, 2017)

Hasil penelitian Fakultas Kedokteran di seluruh Indonesia pada tahun 2016 menunjukkan bahwa prevalensi anemia ibu hamil di Indonesia adalah 50-63\%. Prevalensi anemia ibu hamil di DIY pada tahun 2015 sebesar 14,85\% dan mengalami kenaikan pada tahun 2016 yaitu sebesar 16,09\% dan kembali turun menjadi 14,32 pada tahun 2017. Upaya menurunkan prevalensi anemia ibu hamil harus lebih dilakukan secara optimal mengingat target penurunan jumlah kematian ibu menjadi prioritas permasalahan kesehatan di DIY. Ibu hamil dengan anemia di Kabupaten Kulonprogo 12,88, Bantul 16,32, Gunung Kidul 16,77, Sleman 8,06, Yogyakarta 30,81 (Dinkes DIY, 2017)

Peran pemerintah dalam menangani kejadian anemia pada ibu hamil yaitu dengan memberikan tambah darah minimal 90 tablet selama kehamilan (Kemenkes RI, 2017). Berbagai

(C) Poltekkes Kemenkes Jakarta I

Jl. Wijaya Kusuma No. 47-48 Cilandak Jakarta Selatan, Indonesia email: jurnalquality@poltekkesjakarta1.ac.id kebijakan dan program-program yang ada seperti Upaya Perbaikan Gizi Keluarga (UPGK), Keluarga sadar gizi (KADARZI), pemberian makanan tambahan bagi anak sekolah dan lainnya. Hasil PSG (Pemantauan Status Gizi) 2016 mendapatkan hanya 40,2\% ibu hamil yang mendapatkan TTD minimal 90 tablet lebih rendah dari target nasional tahun 2016 sebesar 85\% (Rahmawati, 2011)

Peningkatkan kepedulian masyarakat dengan adanya kematian ibu terhadap kejadian anemia, Bidan mengajak masyarakat untuk mendukung upaya perbaikan gizi pada ibu hamil dengan pemberian tablet penambah darah, makan yang bergizi dan melakukan pemeriksaan rutin. Anemia pada ibu hamil, yang merupakan salah satu faktor risiko kematian ibu, terjadi karena ibu hamil mengalami defisiensi zat besi. Oleh karena itu, pemberian tablet tambah darah diharapkan mampu mengurangi kasus anemia pada ibu hamil yang pada akhirnya akan menurunkan risiko kematian ibu (Dinkes DIY, 2017)

Anemia pada ibu hamil dihubungkan dengan meningkatnya kelahiran premature, kematian ibu dan anak dan penyakit infeksi. Anemia defisiensi besi pada ibu hamil dapat mempengaruhi pertumbuhan dan perkembangan janin/bayi saat kehamilan maupun setelahnya. Sekitar $41,8 \%$ ibu hamil di seluruh dunia mengalami anemia. Paling tidak setengahnya disebabkan kekurangan zat besi. Ibu hamil dinyatakan anemia jika haemoglobin kurang dari $11 \mathrm{gr} \% / \mathrm{dL}$ (Riskesdas, 2016)

Menurut Lisma (2017) bahwa ibu yang patuh dalam konsumsi tablet tambah darah tidak mengalami anemia. Kejadian anemia pada ibu hamil trimester III dapat dihindari dengan patuh mengkonsumsi tablet Fe sesuai dengan aturan yang telah ditetapkan, selain itu juga bisa didukung dengan pemenuhan nutrisi yang berasal dari makanan yang dikonsumsi dan juga menghindari faktor-faktor yang dapat menjadikan resiko ibu hamil untuk terkena anemia. Hasil penelitian juga menunjukkan bahwa meskipun sudah patuh mengkonsumsi tablet $\mathrm{Fe}$, tetapi masih terdapat ibu hamil yang mengalami kejadian anemia sebanyak 4 orang $(9,5 \%)$ (Lisma, 2017)

Peningkatan kebutuhan zat besi pada ibu hamil tersebut tidak dapat dipenuhi hanya dari makanan, bahkan makanan yang telah mengalami fortifikasi zat besi juga tidak mampu memenuhi kebutuhan ini.

ISSN 2655-2434 
Oleh karenanya pemenuhan zat besi saat hamil juga tergantung pada dua faktor yaitu cadangan zat besi sebelum hamil dan suplemen zat besi selama kehamilan (F, 2011)

Zat besi merupakan mineral yang dibutuhkan tubuh untuk membentuk sel darah merah (haemoglobin). Anemia dalam kehamilan menyebabkan ibu tidak mampu menghadapi kehilangan darah dan membuatnya lebih rentan terhadap infeksi. Anemia juga dapat menimbulkan hipoksia fetal, persalinan premature dan pengaruh terhadap kematian ibu (Proverawati, 2011).

Berdasarkan hasil studi pendahuluan yang telah dilakukan pada tanggal 5 Desember 2018 di Puskesmas Kotagede II terdapat 1024 orang ibu hamil yang melakukan kunjungan pada tahun 2018 namun terdapat 328 orang ibu hamil yang periksa $\mathrm{Hb}$ dengan 161 (49\%) orang ibu hamil yang mengalami anemia. Mengingat pentingnya akibat yang bisa timbul oleh anemia selama kehamilan, maka penulis tertarik untuk meneliti tentang "Kepatuhan konsumsi tablet FE pada Ibu Hamil di Puskesmas Kotagede II Yogyakarta

\section{Metode}

Jenis penelitian kuantitatif menggunakan studi korelasi dengan desain cross sectional yaitu suatu penelitian untuk mengetahui ada tidaknya hubungan hubungan dua atau beberapa variable. Penelitian ini menggunakan survey korelasional yaitu metode penelitian yang dilakukan dengan tujuan menemukan ada tidaknya hubungan tanpa mengetahui hubungan antara tingkat kpeatuhan konsumsi tablet FE dengan kejadian anemia pada ibu hamil (Setiawan, 2011)

Metode pengumpulan data dalam penelitian ini menggunakan studi dokumentasi untuk memperoleh data sekunder dari status ibu dan data primer dengan melakukan pemeriksaan langsung dan memberi kuisioner.

Uji validitas penelitian ini dilakukan pada tanggal 28 Januari 2019 di Puskesmas Kotagede I Yogyakarta dengan responden trimester II dan trimester III. Nomor surat etik No.428/KEPUNISA/I/2019.

\section{Hasil}

Penelitian ini dilakukan di Puskesmas Kotagede II Yogyakarta dengan jumlah sampel 77 ibu hamil trimester II dan trimester III.

Tabel 1. Distribusi Frekuensi Kejadian Anemia pada Ibu Hamil di Puskesmas Kotagede II Yogyakarta

\begin{tabular}{|c|c|c|c|}
\hline & Variabel & Frekuensi & Presentase \\
\hline \multicolumn{4}{|c|}{ Kejadian Anemia } \\
\hline a. & Anemia & 28 & $36,3 \%$ \\
\hline b. & Tidak Anemia & 49 & $63,7 \%$ \\
\hline \multicolumn{4}{|c|}{ Kepatuhan Konsumsi } \\
\hline & Tablet FE & 53 & $69 \%$ \\
\hline a. & Patuh & 24 & $31 \%$ \\
\hline b. & Tidak Patuh & & \\
\hline
\end{tabular}

Sumber: Data Primer 2019

Berdasarkan tabel 1 diketahui bahwa ibu hamil yang tidak anemia sebanyak 49 orang $(63,7 \%)$, namun terdapat kepatuhan konsumsi tablet FE pada ibu hamil yang patuh lebih banyak sebanyak 53 orang $(69 \%)$, dibandingkan ibu hamil yang tidak patuh sebanyak 24 orang (31\%).

Tabel 2. Distribusi Frekuensi Hubungan Kepatuhan Konsumsi Tablet FE dengan Kejadian Anemia pada Ibu Hamil di Puskesmas Kotagede II Yogtakarta

\begin{tabular}{llllll}
\hline \multirow{2}{*}{$\begin{array}{l}\text { Kepatuhan } \\
\text { konsumsi tablet }\end{array}$} & \multicolumn{3}{c}{ Kejadian Anemia } & \\
\cline { 2 - 3 } Fe & Tidak Anemia & Anemia & & Nilai \\
& F & $\%$ & F & $\%$ & $p$ \\
\hline
\end{tabular}

\begin{tabular}{llllll} 
a. Patuh & & \multicolumn{5}{c}{11} & 14,2 & \\
b. Tidak Patuh & 42 & $54,5 \%$ & $\%$ & & 0,000 \\
& 7 & $9,2 \%$ & 17 & 22,1 & \\
& & & $\%$ & &
\end{tabular}

Sumber: Data Primer 2019

Berdasarkan tabel 2, dari 53 responden yang patuh konsumsi tablet FE terdapat $11(14,2 \%)$ yang anemia dan $42(54,5 \%)$ tidak anemia. Sedangkan 24 respoden tidak patuh dalam konsumsi tablet FE terdapat $17(22,1 \%)$ yang anemia dan $7(9,2 \%)$ tidak anemia. Berdasarkan uji Chi Square, pada bagian

ISSN 2655-2434

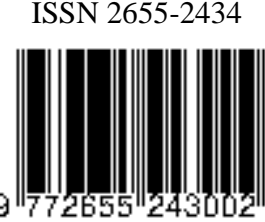


person chi-square terlihat nilai value $0,000\left(\mathrm{x}^{2}\right)$. Karena nilai value $0,000<0,05$ maka dapat disimpulkan terdapat hubungan signifikan antara kepatuhan konsumsi tablet FE dengan kejadian anemia pada ibu hamil di Puskesmas Kotagede II Yogyakarta.

\section{Pembahasan}

\section{Kejadian anemia pada ibu hamil}

Anemia menjadi faktor resiko terjadi perdarahan. Adanya perdarahan pasca persalinan antara lain karena gangguan rahim, pelepasan plasenta, robekan jalan lahir dan gangguan faktor pembekuan darah, resiko akan meningkat antara lain pada ibu yang menderita anemia dan Rahim teregang terlalu besar karena bayi besar (Hermiyanti, 2010)

Pengaruh dan bahaya anemia kehamilan pada masa antenatal adalah berat badan kurang, plasenta previa, eklamsia, KPD, sedangkan pada intratal mengakibatkan tenaga untuk mengedan tidak kuat, perdarahan intranatal, syok, dan masa pascanatal dapat terjadi subinvolusi. Sedangkan pada neonatus dapat terjadi premature, apgar score rendah, gawat janin (Manuaba, 2010). Keseimbangan zat besi dalam tubuh perlu mendapatkan perhatian karena banyaknya zat besi yang dibutuhkan sama dengan banyaknya zat besi yang dikeluarkan, zat besi yang dikeluarkan harus diganti oleh zat besi yang diserap dari makanan (Rahmawati, 2011)

Anemia dalam kehamilan memberi pengaruh kurang baik bagi ibu, baik dalam kehamilan, persalinan, maupun nifas dan masa selanjutnya. Penyulit-penyulit yang dapat timbul akibat anemia adalah keguguran (abortus), kelainan premature, persalinan yang lama akibat otot Rahim di dalam berkontraksi (inersia uteri), syok, infeksi baik saat bersalin maupun pasca bersalin serta anemia yang berat $(<4 \mathrm{gr} \%$ dapat menyebabkan dekompensasi kordis, hipoksia akibat anemia dapat menyebabkan syok dan kematian ibu pada persalinan (Proverawati, 2011). Setiap tablet tambah darah mengandung zat besi yang setara dengan $60 \mathrm{mg}$ besi elemental dalam bentuk Ferro Sulfat, Ferro Fumarat atau Ferro Gluconat dan Asam Folat sebesar 0,400 mg3. Dengan mengkonsumsi tablet rutin setiap hari dapat mengurangi prevalensi anemia dan mencegah terjadinya anemia pada ibu hamil (Fauziah Itsnaini Shofiana, Denok Widari1, 2018)

(C) Poltekkes Kemenkes Jakarta I

J1. Wijaya Kusuma No. 47-48 Cilandak Jakarta Selatan, Indonesia email: jurnalquality@ poltekkesjakarta1.ac.id
Anemia kehamilan didefinisikan WHO sebagai kadar hemoglobin kurang dari $11 \mathrm{~g} / \mathrm{dl}$ atau hematokrit kurang dari $33 \%$ pada setiap waktu pada kehamilan (Sharma, 2010). Definisi anemia kehamilan oleh WHO ini berbeda dengan definisi oleh Center for Disease Control and Prevention $(C D C)$. Definisi anemia kehamilan oleh $C D C$ (2012) mempertimbangkan hemodilusi yang normal terjadi dalam kehamilan di mana kadar hemoglobin kurang dari $11 \mathrm{~g} / \mathrm{dl}$ pada trimester pertama dan ketiga, dan kurang dari 10,5 g/dl pada trimester kedua (Creasy RK, Robert R, Jay D, Charles JL, 2009). Dengan adanya batas anemia yang berbeda pada trimester II dan lainnya, maka setiap hasil pemeriksaan perlu melihat standar batas anemia yang telah ditentukan.

\section{Kepatuhan konsumsi tablet Fe}

Berdasarkan penelitian yang telah dilakukan, didapatkan hasil bahwa ibu hamil di Puskesmas Kotagede II yang patuh mengkonsumsi tablet FE lebih besar sejumlah 24 orang (69\%), namun ibu hamil yang tidak patuh mengkonsumsi tablet FE sejumlah 24 orang (31\%). Kepatuhan mengkonsumsi tablet besi didefinisikan perilaku ibu hamil yang mentaati semua petunjuk yang dianjurkan oleh petugas kesehatandalam mengkonsumsi tablet besi. Kepatuhan konsumsi tablet besi diperoleh melalui perhitungan tablet yang tersisa.

Anemia pada ibu hamil disebabkan karena ketidakpatuhan ibu hamil mengkonsumsi tablet Fe. Ketidakpatuhan ibu hamil dalam mengkonsumsi tablet Fe dipengaruhi oleh peran bidan yang masih kurang terhadap konseling pentingnya mengkonsumsi tablet Fe selama kehamilan.

Dari hasil penelitian yang didapatkan di Puskesmas Kotagede II Yogyakarta, kejadian anemia pada kepatuhan konsusmsi tablet FE, responden ibu hamil yang patuh dan mengalami kejadian anemia sebanyak 11 responden. Dari responden tersebut ibu hamil ditinjau dari kuisioner. Responden anemia dikarenakan cara pengkonsumsian yang menggunakan teh yang dimana dapat menghambat penyerapan, pengaruh usia ibu yang beresiko dan tidakl seringnya mengkonsumsi tablet FE karena prubahan warna kehitaman pada tinja. Ketidak pahaman ibu tersebut menjadikan ibu mengalami anemia.

Banyak faktor yang mempengaruhi terjadinya ISSN 2655-2434 
anemia pada ibu hamil, sehingga jika ibu hamil tidak patuh dalam mengkonsumsi tablet $\mathrm{Fe}$, namun memiliki status gizi yang baik, selalu mengkonsumsi makanan yang mengandung makanan yang mengandung zat besi, masih dalam reproduksi yang sehat maka ibu dapat menjalani kehamilan yang sehat tanpa mengalami kejadian anemia. Oleh karena itu ibu hamil dianjurkan mengkonsumsi makanan yang membentuk sel-sel darah merah seperti hati, daging, kacang-kacangan, sayuran, kuning telur, buah-buahan dan ikan untuk memudahkan penyerapan zat besi (Lisma, 2017). ). Zat besi mempunyai fungsi esensial di dalam tubuh yaitu sebagai alat angkut elektron di dalam sel dan sebagai bagian terpadu berbagai reaksi enzim di dalam jaringan tubuh (Sulistyawati, 2009). Apabila terjadi kekurangan zat besi maka reaksi enzim dalam tubuh akan terganggu

Pemberian tablet zat besi dimulai setelah rasa mual dan muntah hilang yaitu memasuki usia kehamilan 16 minggu, dikonsumsi 1 tablet sehari minimal 90 hari (Salmah, 2010). Pemberian konseling untuk meningkatkan kesadaran ibu hamil seperti memberi informasi mengenai dampak anemia pada ibu maupun pada janin seperti membantu ibu hamil dalam menangani maslaah efek samping yang timbul akibat minum tablet $\mathrm{Fe}$. Peningkatan kepatuhan ibu hamil dalam minum tablet $\mathrm{Fe}$ sehubungan dengan sikap kurang patuh pada sebagian besar ibu hamil. Serta pemberian motivasi dalam upaya meningkatkan kepatuhan ibu hamil minum tablet Fe guna mengurangi kejadian anemia (Wahidah, 2017)

Penelitian ini sesuai dengan penelitian Wahidah (2017) yang menyatakan adanya hubungan antara kepatuhan ibu hamil mengkonsumsi tablet $\mathrm{Fe}$ dengan kejadian anemia dengan tingkat keeratan hubungan rendah. Hal ini diperoleh dari hasil uji statistic dengan $p$ value 0,004 yang bearti $\mathrm{H}_{\mathrm{a}}$ diterima dan $\mathrm{H}_{0}$ ditolak dan nilai koefisien kontingensi 0,339 . responden yang patuh tetapi tidak anemia berjumlah 13 responden $(20,6 \%)$, patuh tetapi mengalami anemia ringan berjumlah 7 responden $(11,1 \%)$, responden yang kurang patuh tetapi tidak anemia berjumlah 9 responden $(14,3 \%)$, responden yang kurang patuh dan mengalami anemia ringan berjumlah 19 responden $(30,2 \%)$ dan kurang patuh dan mengalami anemia sedang berjumlah 5 responden $(7,9 \%)$. Sedangkan

(C) Poltekkes Kemenkes Jakarta I

Jl. Wijaya Kusuma No. 47-48 Cilandak Jakarta Selatan, Indonesia email: jurnalquality@poltekkesjakarta1.ac.id responden yang tidak patuh tetapi tidak anemia berjumlah 3 responden $(4,8 \%)$, tidak patuh dan mengalami anemia ringan berjumlah 4 responden $(6,3 \%)$ dan responden tidak patuh dan mengalami anemia sedang ada 3 responden $(4,8 \%)$.

Suplementasi TTD seharusnya dimulai pada waktu sebelum hamil untuk BBLR dan lahir preterm. Mayoritas wanita di Denmark dan USA direkomendasikan untuk mengonsumsi TTD di awal kehamilan yaitu pada umur kehamilan 10 minggu atau saat kunjungan pertama kali ANC (Milman, 2015). Dengan suplementasi sebelum hamil, diharapkan sel darah merah meningkat sebelum umur kehamilan 12 minggu karena zat besi sangat penting untuk perkembangan awal dari otak janin.

Makin benar cara konsumsi TTD, makin kecil risiko ibu mengalami anemia sebesar $1,1 \mathrm{kali}$ dan tidak bermakna secara statistik $(\mathrm{p}=0,810)$. Bidan telah melakukan upaya untuk mencegah anemia yaitu melakukan cek kadar $\mathrm{Hb}$ pada seluruh ibu hamil dan memberikan TTD sesuai hasil pemeriksaan anemia. Pasien yang anemia diberikan dosis TTD $2 \times 1$, sedangkan yang tidak anemia dengan dosis $1 \times 1$. Suplementasi TTD menjadi pilihan yang tepat untuk mencukupi kebutuhan zat besi selama hamil (Maskume G, Ali SK, 2015). Anemia pada kehamilan di trimester III dapat menyebabkan ibu semakin lemah dan zat besi di dalam darah dibagi untuk pertumbuhan fetus di dalam rahim sehingga mengurangi kapasitas pengikatan zat besi dalam darah ibu (MD, 2014)

\section{Kesimpulan dan Saran}

Berdasarkan hasil penelitian dan pembahasan tentang faktor-faktor yang mempengaruhi kejadian anemia pada ibu hamil di Puskesmas Kotagede II Yogyakarta, maka dapat diambil kesimpulan bahwa Terdapat hubungan bermakna antara kepatuhan konsumsi tablet $\mathrm{Fe}$ dengan kejadian anemia ibu hamil di Puskesmas Kotagede II Yogyakarta.

Ibu hamil di harapkan untuk patuh dalam mengkonsumsi tablet tambah darah, memperhatikan asupan nutrisi yang dikonsumsi, serta memahami faktor risiko anemia berdasarkan usia yang beresiko dan umur kehamilan di setiap trimester untuk menghindari kejadian anemia pada kehamilan .Bagi bidan Puskesmas Kotagede II Yogyakarta untuk ISSN 2655-2434

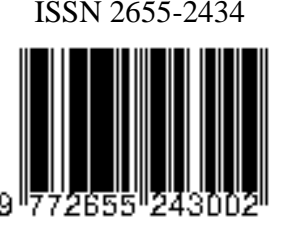


lebih memperhatikan pada ibu hamil yang beresiko anemia dengan melihat buku register untuk memberikan penanganan dengan memberikan biskuit ibu hamil sesuai program pemerintah untuk ibu dengan KEK, dan memberikan konseling untuk mencegah anemia.(Dewi, 2016)

\section{Daftar Pustaka}

Manuaba. (2010). Ilmu Kebidanan, Penyakit Kandungan dan KB. Jakarta: EGC.

Rahmawati. (2011). Asuhan Kebidanan. Jakarta: Victory Inti Cipta.

Riskesdas. (2016). Badan Penelitian dan Pengembangan Kesehatan. Departemen Kesehatan. Jakarta.

Salmah. (2010). Asuhan Kebidanan Antenatal. Jakarta: EGC.

Setiawan. (2011). Metodologi Penelitian Kebidanan. Jakarta: Nuha Medika.

Sulistyawati. (2009). Asuhan Kebidanan Pada Masa kehamilan. jakarta: Nuha Medika.

Creasy RK, Robert R, Jay D, Charles JL, and T. R. (2009). . Maternal fetal Medicine Principles and Practice 6Edition. Philadelphia: Saunders Elsevier.

Dewi, A. (2016). Gizi pada Ibu Hamil. Artikel Kesehatan.

Dinkes DIY. (2017). Profil Kesehatan Provinsi Daerah Istimewa Yogyakarta Tahun 2017. Dinas Kesehatan DIY, 1-224. Retrieved from http://www.depkes.go.id/resources/download/ profil/profil_kes_provinsi_2017/14_diy_2017. pdf.

F, V. (2011). The Consequences of Iron Deficiency and Anemia in Pregnancy on Maternal Health, the Foetus and the Infant.

Fauziah Itsnaini Shofiana, Denok Widari1, S. S. (2018). Pengaruh Usia, Pendidikan, dan

(C) Poltekkes Kemenkes Jakarta I

J1. Wijaya Kusuma No. 47-48 Cilandak Jakarta Selatan, Indonesia email: jurnalquality@poltekkesjakarta1.ac.id
Pengetahuan Terhadap Konsumsi Tablet Tambah Darah pada Ibu Hamil di Puskesmas Maron, Kabupaten Probolinggo. 356-363. https://doi.org/10.2473

Hermiyanti. (2010). Kebijakan Operasional Percepatan Penurunan Angka Kematian. Direktur Bina Kesehatan Ibu Ditjen Kesmas.

JW, C. (2012). Research Design Pendekatan Kualitatif, Kuantitatif, dan Mixed. Yogyakarta: Pustaka Pelajar.

Kementerian Kesehatan RI Badan Penelitian dan Pengembangan. (2018). Hasil Utama Riset Kesehatan Dasar. Kementrian Kesehatan Republik Indonesia, 1-100. https://doi.org/1 Desember 2013

Lisma. (2017). Hubungan Kepatuhan Konsumsi Tablet Fe dengan Kejadian Anemia pada Ibu Hamil Trimester III di Puskesmas Mlati 1 Sleman Yogyakarta.

Maskume G, Ali SK, L. (2015). Risk Factors and Birth Outcomes of Anaemia in Early Pregnancy in a Nulliparous Cohort. PLOS ONE 10 (4).

MD, A. K. and A. (2014). Prevalence of Anemia and Associated Factors among Pregnant Women in an Urban Area of Easthern Ethiopia. Hindawi Publishing Corporation. 7.

Milman, N. (2015). Iron Deficiency and Anemia in Pregnant Women in Malaysia- Still a Significant and Challenging Health Problem. Journal Of Pregnancy and Child Health 2015. 2.

Sharma, J. and M. S. (2010). Anemia in Pregnancy. JIMSA October-Desember 201023 (4):253260.

Wahidah. (2017). Hubungan Kepatuhan Ibu Hamil Mengkonsumsi Tablet FE dengan Kejadian Anemia di Puskesmas Mantrijeron Yogyakarta.
ISSN 2655-2434

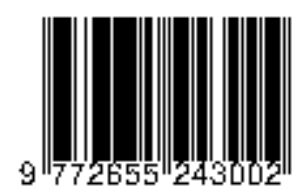

